Earlier studies of quinine concentrations after intramuscular injection were encouraging, ${ }^{11252 \times}$ although none of this work excluded the possibility of transient but toxic peak concentrations. Our results show that a loading dose results in therapeutic plasma concentrations within four hours of injection and that absorption is reliable in patients with moderately severe malaria without the risk of high peaks seen after intramuscular chloroquine (see accompanying paper, p 11). Further work is needed to assess the use of this route in severe, complicated malaria and in children. It is certainly not the ideal route for administration of quinine, but in the absence of the equipment or skills for intravenous infusion intramuscular quinine could be life saving; the risks have been exaggerated.

We are grateful to the director, Dr Sanga Boonbamrung, and staff of Paholpolpayuhasena Hospital, Kanchanaburi, for their cooperation; to Khun Nucharee Cholvilai and Kristin Headlam for secretarial help; and to Dr W H Wernsdorfer of the World Health Organisation, Geneva, for helpful discussion. This study is part of the Wellcome-Mahidol University, Oxford tropical medicine research programme financed by the Wellcome Trust of Great Britain.

\section{References}

1 World Health Organisation Scientific (iroup. Advances in malaria chemotherapy. WHO Tech Report Ser 1984; No 711 .

2 World Health Organisation. Severe and complicated malaria. Trans $R$ Soc Trop Med Hyg in

3 White NJ, Looareesuwan S, Warrell DA, Warrell MJ, Bunnag D, Harinasuta T. Quinine pharmacokinetics and toxicity in cerebral and uncomplicated falciparum malaria. Am $\mathcal{J}$ Med pharmacokinetics

4 White NJ, Chanthavanich P, Krishna S, Bunch C, Silamut K. Quinine disposition kinetics. Br $\mathrm{f}$ Clin Pharmacol 1983:16:399-404.

5 Marchiafava E, Bignami A. On summer-autumn malarial fevers. London: New Sydenham Society, 1894 .
6 Fletcher W'. Studies from the Institute for Medical Research, Kuala Lumpur, Federuted Malay States. London: John Bale, Sons and Danielsson, 1923:24-42.

7 Hall AP. The treatment of severe falciparum malaria. Trans $R$ Soc Trop Med Hyg 1977;71:367-78.

8 Thuriaux MD. Quinine by intravenous infusion for falciparum malaria. Br Med f 1982:285:1429. 9 Spencer HC, Strickland (TT. Malaria. In: Strickland GT, ed. Hunter's tropical medicine, 6th ed. Philadelphia: W B Saunders, 1984:546.

10 W'yler DJ. Malaria. In: Mandell GL, Douglas RG, Bennett JE, eds. Principles and practice of infectious diseases. 2nd ed. New York: Wiley, 1985:1514-22.

11 Shann F, Stace J, Fdstein M. Pharmacokinetics of quinine in children. Pediatrics 1985;106 506-10.

12 Cramer ( , Isaksson B. Quantitative determination of quinidine in plasma. Scand 7 Clin Lab Invest 1963:15:553-6

13 White NJ, Looareesuwan S, Warrell DA, Warrell MJ, Bunnag D, Harinasuta T. Quinine loading dose in cerebral malaria. Am f Trop. Med Hyg 1983;32:1-5.

14 W'arrell DA, Looareesuwan S, W'arrell MJ, et al. Dexamethasone proves deleterious in cerebral malaria. A double blind trial in 100 comatose patients. N Engl f Med 1982;306:313-9.

15 Trigg PL, Wernsdorfer WH, Sheth UK, Onorr E. Intramuscular chloroyuine in children. Lancet 1984:ii: 288 .

16 Gage A. Algid malaria. Therapeutic (jazette 1926:50:77-81.

17 Chopra RN, Rov AC. On the concentration of quinine in the blocod after intravenous and intramuscular injections. Indian Medical (jazetle 1934;69:560-6.

18 Murphy RA. Quinine in the therapeutics of malaria. Indian Medical Gazette 1934;69-566-7.

19 Le Van Hung. Paludisme en grossesse à Saigon. Recue du Paludisme et de Medecine Tropical Van Hung. P. Pac

20 Collomb $\mathrm{H}$, Rey M. Lacces pernicieux palustre en zone d'endemie. Medecine D'A frique Noir 1967;14:29-31

20a (iramberg KPCA. De behandeling van malaria. Ned Tijdschr (jeneeskd 1985;129:611.

21 Government of Papua New Guinea. Standard treatment for common illnesses of children in Papu Nez: Guinea. Port Moresby: Government of Papua New Guinea, 1984.

22 Guyer B, Candy D. Injectable antimalarial therapy in tropical Africa: iatrogenic disease an wasted medical resources. Trans $R$ Soc Trop. Med Hyg 1979;73:230-2

23 Greenblatt DJ, Koch-Weser J. Intramuscular injection of drugs. N Engl f. Med 1976;295:542-6.

24 Cockshott WP. Thompson GI, Howlett LJ, Seelev E.T. Intramuscular or intralipomatou njections? N Engl f. Med 1982:307:356-8.

25 Hall AP. Hanchalay S, Dobersivn EB. Bumnetphund S. Quinine dosage and serum levels in Galciparum malaria Anual Progress Report of the SFATO Reseurch Lahoraton 1974-5:241-50.

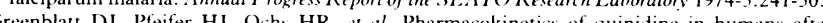
(crence

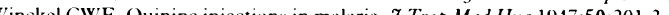

28 Chongsuphajaisiddhi, $T$, Dauruag V, Patchavakessakul V, Kittivattanaku V. Dulvasakdi $B$ Ridthimat $\mathbb{W}$. Treatment of falciparum malaria with intramuscular quinine in a rural area of Thailand. Southeast Asian f Trop Med Hyg 1983:14:220-2

Accepled l Mav 1986

\title{
Divided dose intramuscular regimen and single dose subcutaneous regimen for chloroquine: plasma concentrations and toxicity in patients with malaria
}

\author{
R E PHILLIPS, D A WARRELL, G EDWARDS, YAMUNA GALAGEDERA, \\ R D G THEAKSTON, D T D J ABEYSEKERA， P DISSANAYAKA
}

\begin{abstract}
Adults with malaria in Sri Lanka were treated with parenteral chloroquine diphosphate, either $2.5 \mathrm{mg}$ base/ $\mathrm{kg}$ intramuscularly at $0,1,12,13,24$, and 25 hours or $5 \mathrm{mg}$ base $/ \mathrm{kg}$ subcutaneously at
\end{abstract}

Nuffield Department of Clinical Medicine, University of Oxford

R E PHILLIPS, FRACP, Wellcome lecturer

D A WARRELL, DM, FRCP, clinical reader

Department of Parasitology, Liverpool School of Tropical Medicine, and Department of Pharmacology and Therapeutics, University of Liverpool G EDWARDS, PHD, lecturer

Anuradhapura General Hospital, Anuradhapura, Sri Lanka

YAMUNA GALAGEDERA, MB, BS, house officer

D T D J ABEYSEKERA, MRCP, consultant

P DISSANAYAKA, MRCP, consultant

Department of Tropical Medicine, Liverpool School of Tropical Medicine R D G THEAKSTON, PHD, senior lecturer

Correspondence to: Dr D A Warrell, Faculty of Tropical Medicine, Mahidol University, Bangkok 10400, Thailand.
0, 12, and 24 hours. Both regimens were completed with oral chloroquine phosphate, $5 \mathrm{mg}$ base $/ \mathrm{kg}$, at 36 and 48 hours. Mean peak chloroquine concentrations in the first 12 hours, which were 0.5 (range $0.3-0.6) \mathrm{mg} / 1(1.4(0.9-1.7) \mathrm{mmol} / \mathrm{l})$ with the intramuscular regimen and $0.3(0.2-0.4) \mathrm{mg} / 1(1.0(0.7-1.3) \mathrm{mmol} / \mathrm{l})$ with the subcutaneous regimen $(p<0.05)$, were reached in median times of $90(65-90)$ minutes and 30 (30-60) minutes respectively $(p<0.05)$ after the start of treatment. The mean area under the plasma concentration curve for the first $\mathbf{1 2}$ hours was $1.4(0.9-2.1) \mathrm{mg} / 1 . \mathrm{h}(4.5(2.8-6.4) \mathrm{mmol} / 1 . h)$ after intramuscular administration and $1.8(0.8-2 \cdot 3) \mathrm{mg} / \mathrm{l} . \mathrm{h}(5 \cdot 7(2 \cdot 7-7 \cdot 2) \mathrm{mmol} / \mathrm{l} . \mathrm{h})$ after subcutaneous administration $(p>0 \cdot 1)$. Mean maximum plasma concentrations were higher after intramuscular administration $(0.6(0.4-0.8) \mathrm{mg} / 1(1.7(1.3-2.5) \mathrm{mmol} / \mathrm{l}))$ than after subcutaneous administration $(0.4(0.4-0.5) \mathrm{mg} / 1 \quad(1.3 \quad(1.3-$ $1.5) \mathrm{mmol} / \mathrm{l}))(\mathrm{p}<0.05)$, but both regimens produced satisfactory plasma profiles. Chloroquine resistance was found in the only case of Plasmodium falciparum malaria.

Chloroquine is absorbed rapidly after divided dose intramuscular injection and single dose subcutaneous injection and does not cause hypotension or neurotoxicity in adults. Similar regimens should be evaluated in children before the parenteral use of this drug is abandoned. 


\section{Introduction}

A World Health Organisation (WHO) scientific group has recommended that the use of parenteral chloroquine should be abandoned world wide. ' This arose from fears that patients with malaria who attended clinics after taking chloroquine at home would be at risk of serious toxicity if they were then given a chloroquine injection. Cases of sudden death after intramuscular administration of chloroquine were cited in support of this decision..$^{2-4}$ Abandoning the use of such a widely used and lifesaving drug is a serious matter. The WHO group was influenced by the knowledge that chloroquine was often given by unsupervised paramedical staff who failed to adjust the dosage to the patient's weight, but problems of pretreatment and poor use of injectable drugs apply to all antimalarial drugs, not just chloroquine. Preliminary data suggested that chloroquine given intramuscularly was no less effective and no more toxic than quinine given parenterally. ${ }^{67}$ Chloroquine has been well tried and excellently tolerated in pregnancy and unlike quinine does not cause hypoglycaemia. ${ }^{89} \mathrm{~A}$ serious problem has been the complete lack of information about the pharmacokinetics and toxicity of the drug after parenteral administration.

It is now clear from studies on volunteers that cardiovascular toxicity is likely to occur only when chloroquine enters the circulation very quickly-for example, after intravenous injection. ${ }^{111}$ Rapid absorption after intramuscular injection, a phenomenon observed in animals, ${ }^{12}$ is suspected to have been responsible for the collapse and death of African children who were prone to hypotension because of dehydration and generalised vasodilatation..$^{2-4}$ This type of collapse, however, though often discussed, is virtually undocumented. ${ }^{13}$

We report here the plasma concentrations achieved with, and the toxicity of, parenteral regimens in adults with malaria-namely, divided dose intramuscular injections and single dose subcutaneous injections.

\section{Patients and methods}

At Anuradhapura General Hospital, Sri Lanka, patients were recruited for study if they had malaria that required parenteral treatment. Patients were excluded if they were younger than 15 or older than 65 ; had a history of recent antimalarial treatment; had a mixed infection; were pregnant; or had a second disease. All patients gave informed consent to investigation and treatment. The study was approved by the Ministry of Health and by the hospital medical staff. Patients were admitted to hospital and weighed, and a full history and results of examination were recorded on standard forms. Parasites were counted in thick films. Blood pressure and pulse were recorded before the start of treatment, every 15 minutes for one hour, and then every 30 minutes.

Chloroquine diphosphate (May and Baker) was given in a total dose of $25 \mathrm{mg}$ base $/ \mathrm{kg}$ body weight to patients by one of two regimens chosen randomly. In the divided dose intramuscular regimen chloroquine $2.5 \mathrm{mg}$ base $/ \mathrm{kg}$ was injected into the quadriceps muscle (anterior thigh of alternate legs) on admission and then one, 12, 13, 24, and 25 hours later. In the single dose subcutaneous regimen chloroquine $5 \mathrm{mg}$ base $/ \mathrm{kg}$ was injected sub-

Details of patients and chloroquine administration. Figures are means (ranges) except where indicated

\begin{tabular}{|c|c|c|}
\hline & $\begin{array}{l}\text { Intramuscular } \\
\text { regimen } \\
(\mathbf{n}=7)\end{array}$ & $\begin{array}{l}\text { Subcutaneous } \\
\text { regimen } \\
(\mathrm{n}=8)\end{array}$ \\
\hline Age (years) & $23 \cdot 9(17-31)$ & $27 \cdot 1(20-53)$ \\
\hline Men:women & $5: 2$ & $6: 2$ \\
\hline Weight $(\mathrm{kg})$ & $44 \cdot 9(35 \cdot 5-49 \cdot 0)$ & $46 \cdot 8(41 \cdot 0-56 \cdot 0)$ \\
\hline Parasitaemia (geometric mean $\mu \mathrm{l}$ ) & $10514(4774-23874)$ & $5976(4146-38197)$ \\
\hline No of febrile patients (temperature $>37 \cdot 5^{\circ} \mathrm{C}$ ) & 7 & 7 \\
\hline Temperature $\left({ }^{\circ} \mathrm{C}\right)$ & $38 \cdot 4(37 \cdot 7-39 \cdot 2)$ & $37 \cdot 8(36 \cdot 8-38 \cdot 5)$ \\
\hline Pulse (beats $/ \mathrm{min}$ ) & $75(56-84)$ & $83(60-120)$ \\
\hline \multicolumn{3}{|l|}{ Mean (SD) blood pressure $(\mathrm{mm} \mathrm{Hg})$ : } \\
\hline Systolic (on admission) & $103(11)$ & $102(14)$ \\
\hline Diastolic (on admission) & $70(12)$ & $69(10)$ \\
\hline Systolic (at 30 minutes) & $99(7)$ & $104(14)$ \\
\hline Systolic (at 90 minutes) & $97(12)$ & $103(12)$ \\
\hline \multicolumn{3}{|l|}{ Chloroquine dose ( $\mathrm{mg}$ base): } \\
\hline First 24 hours & $448(354-490)$ & $467(410-524)$ \\
\hline Total & $1122(888-1275)$ & $1164(1022-1400)$ \\
\hline
\end{tabular}

cutaneously at the lateral aspect of the thigh of alternate legs on admission and then 12 and 24 hours later. In both groups of patients the course was completed by giving oral chloroquine phosphate $5 \mathrm{mg}$ base $/ \mathrm{kg}$ at 36 and 48 hours. At 15 minute intervals for one hour after the first dose, and then every 30 minutes, patients were asked about pain at the site of injection and $\bar{z}$ other side effects. Injection sites were examined before every injection and $\mathbb{\Phi}$ then daily until the patients were discharged.

Blood samples were taken, through an indwelling intravenous Teflon catheter kept patent with heparinised saline, before treatment; at five, 15, $\frac{\Omega}{\overline{5}}$ 30,60 , and 90 minutes and two, three, and six hours after the first dose; before and one and two hours after the doses at 12 and 24 hours; and before $\mathbb{D}$ the last dose at 48 hours. Additional samples were taken at 65 and 75 minutes o in patients given intramuscular chloroquine. Blood, dispensed from plastic $\varrho$ syringes into plastic heparinised tubes, was centrifuged at $360 \mathrm{~g}$ for 15 minutes. Plasma, free of the buffy coat, was transferred in plastic pipettes to plastic phials and stored at $-20^{\circ} \mathrm{C}$ for one to two weeks before being transported on dry ice to Liverpool, where it was stored at $-70^{\circ} \mathrm{C}$ until assayed by high performance liquid chromatography. ${ }^{14}$ All glassware was $\frac{\mathrm{O}}{\overline{0}}$ treated with dichlorodimethylsilane $(5 \% \mathrm{vol} / \mathrm{vol}$ in toluene) to minimise drug absorption.

Plasma chloroquine concentrations were analysed with a Hewlett-Packard HP-975 programmable calculator. Statistical comparisons were performed with the Mann-Whitney U test.

\section{Results}

Fourteen patients with Plasmodium vivax malaria and one patient with $P$ falciparum malaria, all of whom had a history of fever and rigors, were $\omega$ studied. All but one were feverish (temperature $>37.5^{\circ} \mathrm{C}$ ) at the time of the of first chloroquine injection. No patient had chloroquine detectable in $\mathscr{\infty}_{\infty}$ pretreatment plasma analysed subsequently in Liverpool. The two groups $(p>0 \cdot 1)$ for age, ratio of men to women, weight, parasitaemia, and total dose 윽 of chloroquine given (table).

Intramuscular chloroquine-All patients complained of pain at the site of injection, but none thought it severe; it lasted from 15 minutes to two hours. They did not complain of discomfort on moving the muscle once the pain $\overrightarrow{0}$ had subsided, and none had any sign of induration or abscess formation. \& There was a non-significant fall $(\mathrm{p}>0.05)$ in blood pressure 30 and 90 minutes after the first injection (table), and no patient had visual or other neurological symptoms or signs. Plasma chloroquine concentrations (fig l) varied considerably among patients. Absorption was rapid, and in five of the

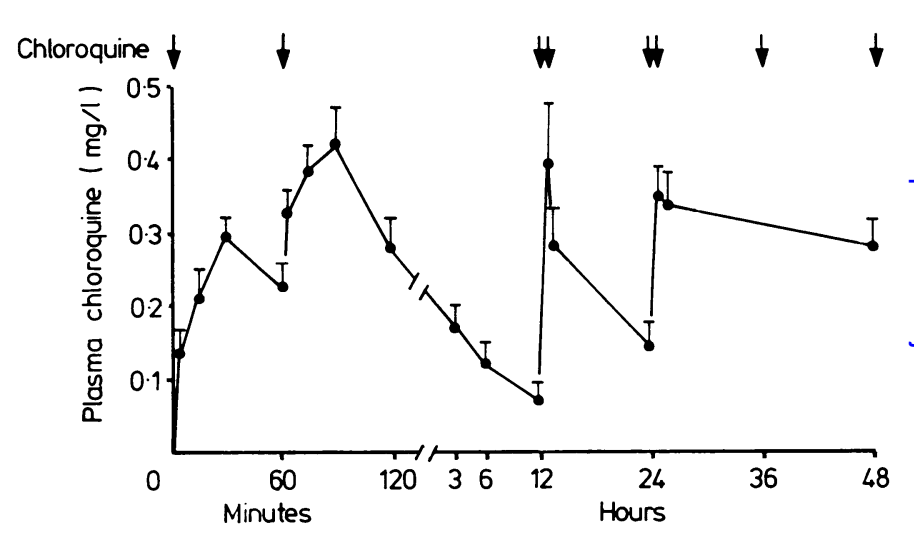

FIG 1-Plasma chloroquine concentrations after intramuscular injection $(2.5 \mathrm{mg}$. base $/ \mathrm{kg}$ body weight) at $0,1,12,13,24$, and 25 hours and oral administration of $\mathrm{N}$ chloroquine phosphate $(5 \mathrm{mg}$ base $/ \mathrm{kg}$ ) at 36 and 48 hours. Values are means (SEM).

Conversion: traditional units to $S I-1 \mathrm{mg}$ chloroquine $\approx 3 \mathrm{mmol}$.

seven patients plasma concentrations at 30 minutes exceeded those at one hour. The mean peak plasma chloroquine concentration during the first 12 hours was $0.5($ range $0.3-0.6) \mathrm{mg} / 1(1 \cdot 4(0 \cdot 9-1 \cdot 7) \mathrm{mmol} / \mathrm{l})$ and was reached $\frac{0}{\mathbb{D}}$ a median of $90(65-90)$ minutes after the first injection. The mean peak concentration after the second divided dose (given at 12 and 13 hours) was $0.5(0.3-0.6) \mathrm{mg} / \mathrm{l}(1.4(0.9-1.7) \mathrm{mmol} / \mathrm{l})$. The mean highest concentration $(0.6(0.4-0.8) \mathrm{mg} / \mathrm{l}(1.7(1 \cdot 3-2 \cdot 5) \mathrm{mmol} / \mathrm{l}))$ was reached 30 minutes to 25 hours (median 90 minutes) after the start of treatment.

Subcutaneous chloroquine-Subcutaneous injection did not seem to be any more or less painful than intramuscular injection. There was no fall in blood pressure and no systemic effects. Figure 2 shows the plasma chloroquine $\stackrel{?}{?}$ 


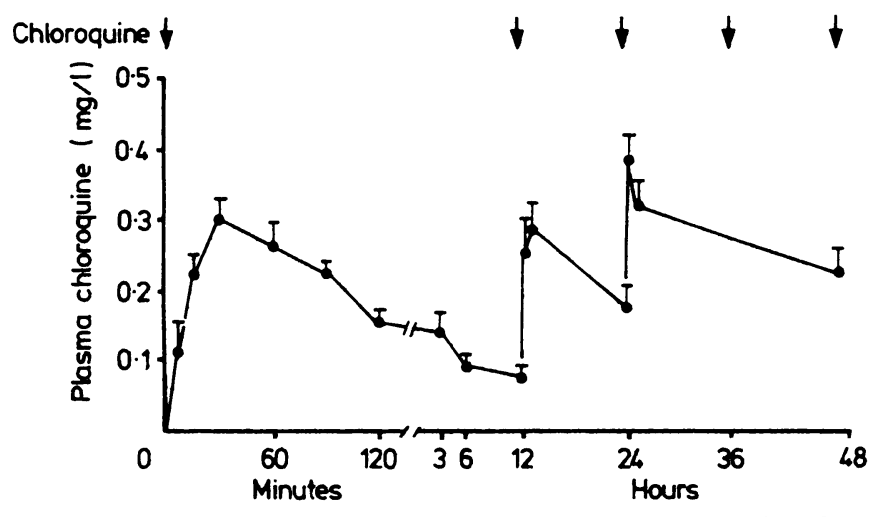

FIG 2-Plasma chloroquine concentrations after subcutaneous injection (5 mg base $/ \mathrm{kg}$ ) at 0,12 , and 24 hours and oral administration of chloroquine phosphate at 36 and 48 hours. Values are means (SEM).

Conversion: traditional units to $S I-1 \mathrm{mg}$ chloroquine $\approx 3 \mathrm{mmol}$.

concentrations. Absorption was rapid. The mean peak plasma concentration during the first 12 hours was $0.3(0.2-0.4) \mathrm{mg} / 1(1.0(0.7-1.3) \mathrm{mmol} / \mathrm{l})$ and was reached a median of $30(30-60)$ minutes after injection. The highest concentrations, which averaged $0.4(0.4-0.5) \mathrm{mg} / 1(1.3(1.3-1.5) \mathrm{mmol} / \mathrm{l})$, were found 13 hours (in two patients), 14 hours (two), and 25 hours (four) after the first injection.

Comparison of regimens-Plasma chloroquine concentrations were not significantly different between the two regimens at five, 15,30 , and 60 minutes. The time taken to reach maximum concentration in the 12 hours after the start of treatment was significantly shorter for the subcutaneous regimen $(p<0.05)$, but the overall peak concentration was significantly higher after the intramuscular regimen $(p<0.05)$. There was no significant difference between the two regimens in the areas under the plasma concentration curves for the first 12 hours (subcutaneous: mean $1.8(0.8$ $2 \cdot 3) \mathrm{mg} / \mathrm{l} . \mathrm{h}(5 \cdot 7(2 \cdot 7-7 \cdot 2) \mathrm{mmol} / \mathrm{h})$; intramuscular: $1 \cdot 4(0 \cdot 9 \cdot 2 \cdot 1) \mathrm{mg} / 1 . \mathrm{h}(4 \cdot 5$ $(2 \cdot 8-6 \cdot 4) \mathrm{mmol} / \mathrm{l} . \mathrm{h})(\mathrm{p}>0 \cdot 1)$.

Therapeutic effect-All patients with vivax malaria responded well. The only patient with falciparum malaria, a 31 year old woman admitted with parasitaemia of 13193 trophozoites/ $\mu$ l, responded to treatment by showing clearance of parasites at three days but returned on day 14 with recurrent parasitaemia.

\section{Discussion}

For decades intramuscular injection of chloroquine has been used throughout the tropics to treat malaria. By this method rural health workers have been able to treat patients who were vomiting or comatose, and the practice was rarely questioned, despite some reports of sudden death in children. In retrospect, it is surprising that the chemotherapy of a life threatening infection should have relied on a drug whose pharmacokinetics were so poorly understood. Until recently there had been no attempt to define the pharmacokinetics and toxicity of chloroquine in man, yet there were sufficient data from animal experiments and patients who had taken overdoses to suggest that cardiovascular poisoning was a serious risk. ${ }^{12}$ is When the WHO became aware of a high incidence of self medication with chloroquine $\mathrm{e}^{16}$ it decided to recommend that parenteral use of this drug should be abandoned because it feared that toxic concentrations could result if intramuscular injections were given. ${ }^{1}$ After this decision there was much uncertainty about parenteral chemotherapy for malaria; chloroquine has had a generally good record of safety for nearly 40 years and the only alternative drug, quinine, is also potentially toxic.

The critical data needed to make an informed decision about chloroquine were the kinetics of absorption and disposition. This deficiency has been partly corrected by recent studies in volunteers and patients with malaria. After intravenous injection transient but very high plasma chloroquine concentrations occur and all subjects report side effects such as dizziness and blurred vision. ${ }^{11}$ Hypotension and prolongation of the electrocardiographic QRS interval were detected in one study, in which cardiovascular effects were specifically sought. ${ }^{11}$ Absorption in animals after intramuscular injection was rapid, ${ }^{12}$ and the present study shows that this is also true in man, whether the drug is injected into muscle or sub- cutaneous tissue. Peak chloroquine concentrations were significantly higher and were reached sooner during the intramuscular regimen, but relative bioavailability as judged by the area under the plasma concentration curve was similar. Peak concentrations were lower than those detected in volunteers given intravenous injections of similar doses, ${ }^{10}$ and the patients with malaria did not experience a change in blood pressure or neurotoxic effects.

Studies in areas where $P$ falciparum remained fully sensitive to chloroquine have shown no advantage for quinine, which is more expensive.$^{67}$ Both drugs have potential cardiovascular toxicity, ${ }^{15}$ particularly when given in overdose or by rapid intravenous injection. ${ }^{18}$ Quinine has the additional risks of refractory hyperinsulinaemic hypoglycaemia, ${ }^{19}$ especially in pregnancy, ${ }^{8}$ an association with blackwater fever, ${ }^{20}$ and the potential for damage to tissue, even when injections are sterile. ${ }^{21}$ Chloroquine has an excellent safety record in pregnancy, ${ }^{22}$ and cerebral malaria in children has responded well to parenteral chloroquine. ${ }^{23}$ Chloroquine was rapidly absorbed after subcutaneous injection in these Sri Lankan adults and in Zambians (N J White et al, unpublished findings), but in severe malaria with shock cutaneous perfusion may be sufficiently poor to dangerously impede systemic absorption of the drug. Under circumstances where therapeutic blood concentrations must be reached as quickly and reliably as possible, such as in cerebral malaria, slow intravenous (or even continuous) infusion is the best way to give chloroquine parenterally. ${ }^{24}$ As a compromise where intravenous equipment is not available divided dose intramuscular injections, correctly adjusted for weight, allow therapeutic chloroquine concentrations to be reached quickly and reduce the risk of transient but potentially dangerous peaks that could occur if $5 \mathrm{mg}$ base $/ \mathrm{kg}$ was injected as a single dose. In shocked patients, however, absorption of chloroquine from muscle may be inadequate so this route should not be relied on unless it is impossible to set up an intravenous infusion.

Studies of intravenous chloroquine injection have suggested that dangerous concentrations occur when the drug enters the circulation more rapidly than it can be dispersed." This could happen if absorption after intramuscular injection was particularly rapid, and this possibility must be investigated in children. Recent treatment with chloroquine could increase the risk of high concentrations, ${ }^{16}$ but the rate of entry of the drug into the circulation, rather than the dose, seems to be the most important determinant of acute toxicity. ${ }^{11}$

Debate over the relative merits of quinine and chloroquine will continue while $P$ falciparum remains sensitive to chloroquine in some parts of the world. The rapid spread of chloroquine resistance westwards in Africa and Asia (shown by the patient with falciparum malaria described above and other recent reports ${ }^{25}$ ) may ultimately make this discussion redundant. For the time being, however, quinine is not an ideal substitute for chloroquine world wide. Radical cure with quinine alone is difficult to achieve, as the drug can cause serious toxicity, and it has never been shown to be superior to chloroquine for infections sensitive to chloroquine. Acute chloroquine toxicity seems to be predictable and can be circumvented by controlled administration. There are too few alternative drugs for us to abandon chloroquine for the treatment of severe malaria; the recommendation to do so should be revised.

We thank Angela Davies for measuring chloroquine concentrations in Liverpool; the director and staff of Anuradhapura General Hospital and the Sri Lankan Ministry of Health for enthusiastic support; Dr U T Vitarana, director of the Medical Research Institute, and other senior medical colleagues in Colombo, especially Drs Nihal Perera, Dennis Aloysius, and C G Uragoda, for unstinting help with organisation; and Khun Nucharee Cholvilai for secretarial help. This study is part of the Wellcome-Mahidol University, Oxford tropical medicine research programme funded by the Wellcome Trust of Great Britain.

\section{References}

1 World Health Organisation Scientific Group. Advances in malaria chemotherapy. WHO Tech Rep Ser 1984; No 711 .

2 Williams ARF. Malaria in children. BrMed $\mathcal{J}$ 1966;ii: 1531.

3 Tuboku-Metzger AF. Chemotherapy of malaria. BrMed J 1964;i:1378

4 Geddes TG. Acute malaria in newborn infants. Br Med J 1970;ii:711. 
5 World Health Organisation. Severe and complicated falciparum malaria. Trans $R$ Soc Trop Med $H y g$ (suppl) (in press).

6 Van Poucke G. A comparative study on the use of intramuscular chloroquine and quinine (as quinimax) in the treatment of uncomplicated falciparum malaria in adults. East Afr Med $\mathcal{J}$ 1979;56:158-62.

7 Maguire MJ: The management of cerebral malaria in African children. East Afr Med $\mathcal{J}$ $1983 ; 60: 260-5$

8 Looareesuwan S, Phillips RE, White NJ, et al. Quinine and severe falciparum malaria in late pregnancy. Lancet 1985 ;ii:4-8.

9 Phillips RE, Looareesuwan S, White NJ, et al. Hypoglycaemia and antimalarial drugs: quinidine and release of insulin. Br Med f 1986;292:1319-21.

10 Gustafsson LL, Walker O, Alvan G, et al. Disposition of chloroquine in man after single intravenous and oral doses. Br f Clin Pharmacol 1983;15:471-9.

11 Looareesuwan S, White NJ, Chanthavanich P, et al. Cardiovascular toxicity and distribution kinetics of intravenous chloroquine. $\mathrm{Br} \mathcal{J} \mathrm{Clin}$ Pharmacol (in press).

12 Salako LA, Adelusi SA. Plasma, white blood and red blood cell kinetics of chloroquine after oral and parenteral administration in rabbits. Archives Internationales de Pharmacodynamie et de Therapie 1983;261:4-15.

13 World Health Organisation. Pharmacology of compounds in current use. In: Bruce-Chwatt LJ, ed. Chemotherapy of malaria. 2nd ed. Geneva: WHO, 1981:69.

14 Alvan G, Ekman L, Lindstrom B. Determination of chloroquine and its de-ethylated metabolite in plasma, red blood cells and urine by liquid chromatography. $\mathcal{f}$ Chromatogr 1982;229:241-7.

15 Kubasta M, Vykydal M, Zmeskal A, Gikalovova I. Cardiotoxicity of chloroquine in rabbits. Ethiop Med J 1968;5:189-202.
16 Trigg PI, Wernsdorfer WH, Sheth UK, Onoir E Intramuscular chloroquine in children Lancet 1984;ii:288.

17 White NJ, Looareesuwan S, Warrell DA. Quinine and quinidine: a comparison of EKG effects after and during the treatment of malaria. $\mathcal{f}$ Cardiovasc Pharmacol 1983;5:173-5.

18 White NJ, Chanthavanich P, Krishna S, Bunch C, Silamut K. Quinine disposition kinetics. Br $\mathcal{F}$ Clin Pharmacol 1983;16:399-403.

19 Phillips RE, Warrell DA, Looareesuwan S, et al. Effectiveness of SMS 201-995, a synthetic long acting somatostatin analogue in treatment of quinine induced hyperinsulinaemia. Lancet 1986;i:713-6.

20 Phillips RE, Looareesuwan S, Warrell DA, Lee SH, Weatherall DJ. Anaemia and falciparum malaria. Qf Med 1985;57:803 (abstract).

21 Fletcher W. Studies from the Institute for Medical Research, Kuala Lumpur, Federated Malay States, London: John Bale, Sons and Danielsson, 1923:24-42.

22 Wolfe MS, Cordero JF. Safety of chloroquine in chemosuppression of malaria during pregnancy. BrMed 7 1985;290:1466-7.

23 Rothe H. 100 cases of cerebral malaria. East Afr Med 7 1956:33:405-7.

24 Edwards G, Davies AJ, Phillips RE, etal. Plafrmacosentrations and oxicity of chloroune afer slow intravenous infusion in patients with falciparum malaria. Ann Trop Med Parasitol (in . press)

25 Ratnapala R, Subramaniam K, Yapabandara MGM, Fernando WP. Chloroquine resistant $\overrightarrow{\bar{D}}$ falciparum malaria in Sri Lanka. Sri Lanka Medical fournal 1984;29:135-45.

(Accepted I May 1986)

\section{SHORT REPORTS}

\section{Ultrasound diagnosis of bile duct calculi}

Diagnosing choledocholithiasis by ultrasound is difficult and most series have reported sensitivities of $8-30 \% .{ }^{12}$ The calibre of the common duct is not a reliable indicator since up to a third of patients with choledocholithiasis have ducts of normal size ${ }^{3}$ and, conversely, dilated but non-obstructed ducts are common in patients who have had cholecystectomy. ${ }^{4}$ We investigated the role of real time ultrasound as a screening test for selecting patients with suspected biliary tract disease for retrograde cholangiography and aimed at determining whether we could reliably predict or exclude bile duct disease by combining the ultrasonic findings in the bile duct with those in the gall bladder and the results of biochemical liver function tests.

\section{Patients, methods, and results}

A total of 104 patients ( 41 men, 63 women; mean age 60 years, range 21-88) had an ultrasound examination performed by one of two experienced radiologists some abnormality or was technically unsatisfactory in 19 of 27 patients with dilatation of the common duct only or other biliary disorders besides choledocho- $-\circ$ lithiasis its specificity was only $68 \%$.

Gall bladder calculi on ultrasound and liver function abnormalities-In 47 patients $\underset{\infty}{\omega}$ with gall bladders in situ gall bladder calculi were significantly more common in those with choledocholithiasis than in those without $(12 / 16(75 \%) v 11 / 31(35 \%) ; \omega$ $\left.\chi^{2}=6.67 ; p<0.01\right)$, as were liver function abnormalities in those with choledocho- 은 lithiasis compared with those with normal cholangiograms $(31 / 36(86 \%) v 7 / 39 \mathrm{Gr}$ $\left.(18 \%) ; \chi^{2}=34.8 ; \mathrm{p}<0.001\right)$. The predictive values of normal ultrasonic ap- $C$ pearances in the gall bladder and normal liver function values in excluding choledocholithiasis were $83 \%$ and $86 \%$ respectively.

\section{Comment}

Calculi are common in the bile duct, particularly in the elderly, when the presentation is often atypical and non-specific, and retrograde cholangiography is not always available for accurate diagnosis. Conversely, many cholangiograms to exclude stones in the common duct are performed $\mathbb{D}$ unnecessarily as a result of the reported unreliability of ultrasound.

Results of common duct and gall bladder ultrasound and liver function tests

\begin{tabular}{|c|c|c|c|c|c|c|}
\hline \multirow[b]{2}{*}{$\begin{array}{l}\text { Findings on } \\
\text { cholangiography }\end{array}$} & \multicolumn{2}{|c|}{ Results of common duct ultrasound $(n=102)^{\star}$} & \multicolumn{2}{|c|}{ Results of gall bladder ultrasound $(n=47)$} & \multicolumn{2}{|c|}{ Liver function values $(n=75)$} \\
\hline & Normal & $\begin{array}{l}\text { Abnormal or } \\
\text { technical failure }\end{array}$ & Calculi present & Calculi absent & Normal & Abnormal \\
\hline $\begin{array}{l}\text { Calculi } \\
\text { No calculi }\end{array}$ & $\stackrel{1}{45 t}$ & $\begin{array}{l}35 \\
21 \ddagger\end{array}$ & $\begin{array}{l}12 \\
11\end{array}$ & $\begin{array}{r}4 \\
20\end{array}$ & $\begin{array}{r}5 \\
32\end{array}$ & $\begin{array}{r}31 \\
7\end{array}$ \\
\hline Total & 46 & 56 & 23 & 24 & 37 & 38 \\
\hline
\end{tabular}

*Two patients with indeterminate duct calibre on cholangiography excluded from further analysis.

†Thirty seven patients had a normal cholangiogram.

$\ddagger$ Nineteen patients had other disease or dilatation of common duct only.

before retrograde cholangiography. Particular note was taken of the presence of calculi in the gall bladder and common duct and the calibre of intrahepatic and extrahepatic ducts. The upper limit of normal calibre of the common duct was 6 $\mathrm{mm}$ on ultrasound and $10.5 \mathrm{~mm}$, corrected for magnification, on cholangiography. The ultrasound was deemed a technical failure when no part of the common duct was visualised, though in some of these cases the gall bladder was examined. All patients had biochemical liver function tests performed within 24 hours of the examinations. The table summarises the results.

Ultrasonic findings in common duct-Of 36 patients with calculi in the common duct detected by cholangiography, ultrasound correctly identified 20, in three of whom the duct was of normal calibre, giving a sensitivity of $56 \%$. A further 10 had a dilated common duct diagnosed correctly, so that $83 \%$ of patients with calculi in the common duct had some abnormality of the duct noted at ultrasound. If five patients whose ultrasound examination was technically unsatisfactory are excluded this figure rises to $97 \%$. Of 39 patients with normal cholangiograms, ultrasound was in agreement in 37, giving a predictive value of a normal finding in excluding choledocholithiasis of $\mathbf{9 8 \%}$. Nevertheless, because ultrasound showed
In this series we have shown how radiologists with a special interest can improve sensitivity enough to make ultrasound a valuable screening test for choledocholithiasis. In practical terms, if ultrasound visualisation of calculi in the common duct or dilatation or a technically unsatisfactory examination $\mathbb{D}$ were taken as criteria for proceeding to direct cholangiography only a single ? patient with choledocholithiasis would have been missed and only 14 of 104 cholangiograms would have been "unnecessary." Of particular interest, however, was the combined predictive value of an ultrasonically acalculous gall bladder and normal liver function results in excluding choledocholithiasis $\mathbb{\mathbb { D }}$ $-100 \%$ in this series-since all patients with choledocholithiasis who had an intact gall bladder had either cholelithiasis or abnormal liver function, or both.

In conclusion, this study shows that, though stones in the common duct remain elusive to ultrasound, real time ultrasonography, performed by experienced radiologists, and biochemical liver function tests provide a 